\title{
Total electron content variation over HALY (Al-Jouf), Saudi Arabia and comparison with IRI-2012 and IRI- 2016 models
}

\author{
Sunil Kumar Sharma \\ College of Computer and Information Sciences, Majmaah University, Majmaah- 11952, Saudi Arabia \\ Correspondence: s.sharma@mu.edu.sa
}

\begin{abstract}
Ionospheric perdition studies are very few over Saudi Arabia due to less availability of data measurement. Although such kind of studies have been carried out all over the world, there still remains scope to ascertain prediction error in this country. Hence, in the current study, the ionospheric variation from April 2016 to February 2018 (almost 22 months) was studied over a GPS site HALY (29.140N; 36.10 0E), Al-Jouf, Saudi Arabia. Diurnal, monthly and seasonal ionospheric variations were investigated and compared with the existing global IRI (IRI 2012 and IRI 2016) models. Percentage deviation between observed and modeled TEC variation values indicated largescale deviation around $200 \%$ during the time of storm. Results showed that the IRI 2012 model had the lowest Root Mean Square Error (RMSE) value (2.7437) during the September Equinox while IRI2016 showed the highest RMSE magnitudes (3.0166) during the December Solstice. In some seasons, the RMSE values were observed to be better for IRI 2012 while on other occasions, it emerged that IRI 2016 yielded more accurate results. Such variations indicate that even the most updated version of the IRI 2016 model is unable to provide perfect estimation and the requirement of further research and improvement in this field cannot be denied.
\end{abstract}

Keywords: GPS, IRI-2012, IRI-2016, Saudi Arabia

\section{Introduction}

Global Navigation Satellite Systems (GNSS) signals are the combination of other global navigation systems such as GPS from United States, GLONASS from Russia, Galileo from Europe and local systems like COMPASS from China, IRNSS from India and QZSS from Japan. The signals from these networks are used for the purpose of navigation and play an important role in atmospheric studies by using forecasting methods. Extracting the atmospheric delay of the wet part of the troposphere is also possible nowadays. Ground-based GNSS receivers can estimate Integrated Precipitable Water Vapor (IPWV) and Precipitable Water Vapor in all weather conditions [1-6]. GNSS signals also consider the impact of rainfall, theoretical results pertaining to which have been discussed by Solheim et al [7]. The sensitivity of the total delay in the presence of severe precipitation has been analyzed by several authors [e.g. 8, 9]. Several studies have been carried out by using highprecision GNSS based on crustal deformation and Strain analysis [10-13]. The space weather plays a significant role in our day-to-day life, including in the advancement of the high-tech military systems based upon the highest strata of the Earth's atmosphere and ionosphere. The study of ionosphere contributes significantly to the information system, health, satellite communications, air traffic control, navigation and positioning system and space science. The Earth's upper atmosphere is ionized by the extreme ultraviolet radiation generated in the ionosphere. The geomagnetic storms are mainly responsible for the increased/decreased electron density, total electron content, and thickness of the ionosphere.

To study the GNSS and ionospheric variations the most significant parameter to be evaluated is the Total Electron Contents (TEC). Recent advancement in the GNSS technology has enabled the measurement of the Radio Occultation (RO) of the Earth' atmosphere with the help of the GNSS satellite constellation of Low Earth Orbit (LEO) satellites. Various models have been proposed to 
increase enhanced applications of ionospheric data and GNSS in several studies. Several empirical models have been developed for the estimation TEC, e.g. electron density profiler, NeQuick and International Reference Ionosphere (IRI) etc. The IRI model estimates various parameters like electron temperature, ion temperature, and monthly mean values for electron ion density [14-16]. The availability of GNSS data plays a highly significant role in the validation of the estimated values of the empirical models in the given region. In the Saudi Arabian region, the availability of the experimental data measurement is very low, due to the slightly low prediction ability of the ionospheric model. Though the IRI model versions are updated frequently to obtain a better estimation, there still remains scope for improvement with regard to validation with the GNSS ionosonde and coherent scatter radar. Extensive research has been conducted so far with the use of IRI models for different equilateral and low-latitude locations [17-28].The lack of coherence is observed especially during geomagnetic disturbance. Recently, Sharma et al [29] studied the feasibility of the NeQuick-2 model to explore TEC variation in the ionosphere over the Manama, Bahrain region and observed that the data was in good agreement during a specific period; however, the need of further experimentation and more scientific efforts was stressed, for improving the empirical model and ensuring better representation of a realistic model. Hence, in the current study, the validity of IRI models (IRI 2012 and IRI 2016) has been checked in one of the UNAVCO GPS sites named HALY, which is located at Al-Jouf, Saudi Arabia.

\section{Data and Methods:}

The present study attempted to assess the reliability of IRI-2012 and IRI-2016 models by comparing the variability with GPS-derived TEC from a UNAVCO GPS site named HALY located at over Al-Jouf, Saudi Arabia (Fig. 1).The IRI-2012 and IRI-2016 models can be accessed (https://ccmc.gsfc.nasa.gov/modelweb/models/iri2012_vitmo.php) and https://ccmc.gsfc.nasa.gov/modelweb/models/iri2016_vitmo.php), respectively. The aim of this study is to compare the IRI-2012 and IRI-2016 models by using the GPS-TEC values obtained over Al-Jouf, Saudi Arabia, using almost two years GPS data set from March 2016 to February 2018. The GPS data in RINEX format have been accessed from UNAVCO website and processed with GPS-TEC analysis program provide by GOPI-Seemala [30]. The program first calculates slant TEC (STEC) value and then converts them into vertical TEC (VTEC) by using the single layer model (SLM) mapping function, which assumes the ionospheric electron density to be concentrated in a thin shell at $350 \mathrm{~km}$ above the Earth. BRDC file was downloaded from the CDDIS server (ftp://ftp.aiub.unibe.ch/CODE) automatically. The following formula was used to convert VTEC from STEC:

$$
V T E C=S T E C \times \sqrt{1-\left(\frac{R_{E} \cos \alpha}{R_{E}+h_{\max }}\right)^{2}}
$$

Where $\mathrm{R}_{\mathrm{E}}$ stands for radius of the Earth $(6378 \mathrm{~km}), \alpha$ is the elevation angle and $\mathrm{h}_{\max }(350 \mathrm{~km})$ is the ionospheric thin shell above the Earth. The elevation angle of $20^{\circ}$ was selected to avoid the multipath error. 


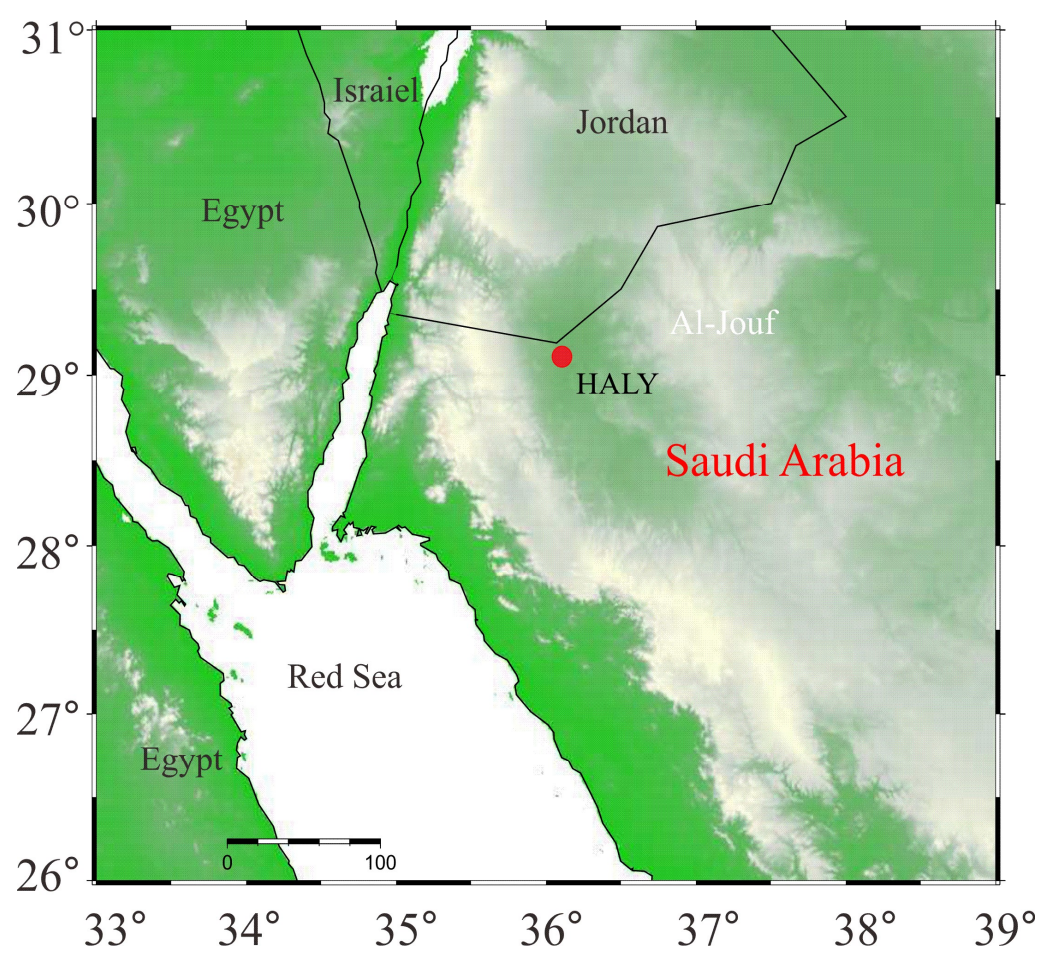

Figure 1. Location of HALY GPS site over Al-Jouf Saudi Arabia.

Percentage deviation from GPS-TEC values and IRI models were estimated for comparison purpose by using the following equation [31]

$$
\Delta T E C(\%)=\left(\frac{G P S_{T E C}-M_{0 d e l}}{G P S_{T E C}}\right) \times 100
$$

Root mean square error was calculated to check the comparison of seasonal variation by using the formula given below:

$$
R M S E=\sqrt{\left.\sum_{T E C=1}^{N} \frac{1}{N}\left(G P S_{T E C}-M_{o d e l}\right)_{T E C}\right)^{2}}
$$

Where GPSTEс stands for GPS-TEC values and Modeltec stands for IRI models TEC values. N denotes the number of observations.

\section{Results and Discussion}

\subsection{Diurnal VTEC variation}

The earth rotates on its axis and takes around twenty-four hours for one rotation; such type of motion of earth is known as rotational motion. VTEC activity is due to the rotational motion of the earth and it keeps changing with time at a particular location. Activity change of VTEC variation is called diurnal VTEC variation. In the current study, the VTEC variation over HALY GPS site located in Saudi Arabia has been checked for the year of April 2016 to February 2018 and compared with IRI models. The contour plot of these variations has been plotted in Fig. 2. It may be observed that the VTEC of the year 2017 varied from around 1 TECU to 20 TECU (Fig. 2a). At the starting of the day, from $0.00 \mathrm{UT}$ till $4.00 \mathrm{UT}$, the VTEC variation was found to be low, and such was observed round the year. A small variation was observed around the day 350 , which may be attributed to a storm day or to an error in VTEC measurement. However, after 4.00 UT the VTEC variation became high till 10.00 UT. It may be noticed the VTEC values were rather high between 7.00 UT to 13.00 UT. The variation 
of VTEC was not constant between these periods and it kept on varying all over the year. It was very low, around $4 \mathrm{TECU}$, on the first day of the year and started to increase around the $40^{\text {th }}$ day of the year. The VTEC value became around 12 TECU on the $50^{\text {th }}$ day of the year and sometimes touched 18 TECU between the 100-150 th days. The value of VTEC was very low again between the 200-250 $0^{\text {th }}$ day (around 3 TECU) and began to increase between the 250-325 th day of the year 2017. The VTEC value again became low from the $325^{\text {th }}$ day till the end of the year. It may be noticed that the VTEC variation after 13.00 UT was high during the 50-300th day, but declined with time and became very low after 19.00 UT. By the end of the day, the variation is same all over the year, as it was in the starting of the day. Such variations have been discussed by several authors [32-34]. While the diurnal variation of VTEC depends on the rotational motion of the earth, the seasonal variation is caused by the revolutionary motion.

The diurnal VTEC variation of IRI models (IRI-2012 and IRI-2016) for the year 2017 at the HALY site have been plotted in Fig. 2b and Fig. 2c. Both IRI models contour plots show low VTEC values at the start and end of the day but touch higher values between the hours of 6:00 UT to 14:00 UT; same pattern was observed at the HALY GPS site. The notable difference is the discrepancy of VTEC values. The GPS VTEC discrepancies were rather high, but the IRI-2012 models showed a pattern of constant variation. Remarkably, smaller discrepancies were observed in the IRI-2016 model compared to the IRI-2012 model. IRI-2016 has the newest upgradation in the model after IRI-2012, having included two new F2-peak height hmF2 modeling selections with their data sources from ionosonde quantities and COSMIC radio occultation. Most importantly, the IRI Real-Time Assimilative Modeling (IRTAM) can even cope with the times of disturbed ionospheric situations, having inserted a number of digitonide limitations. However, the IRI-2016 model still unable to reach and perfect model the VTEC variation.

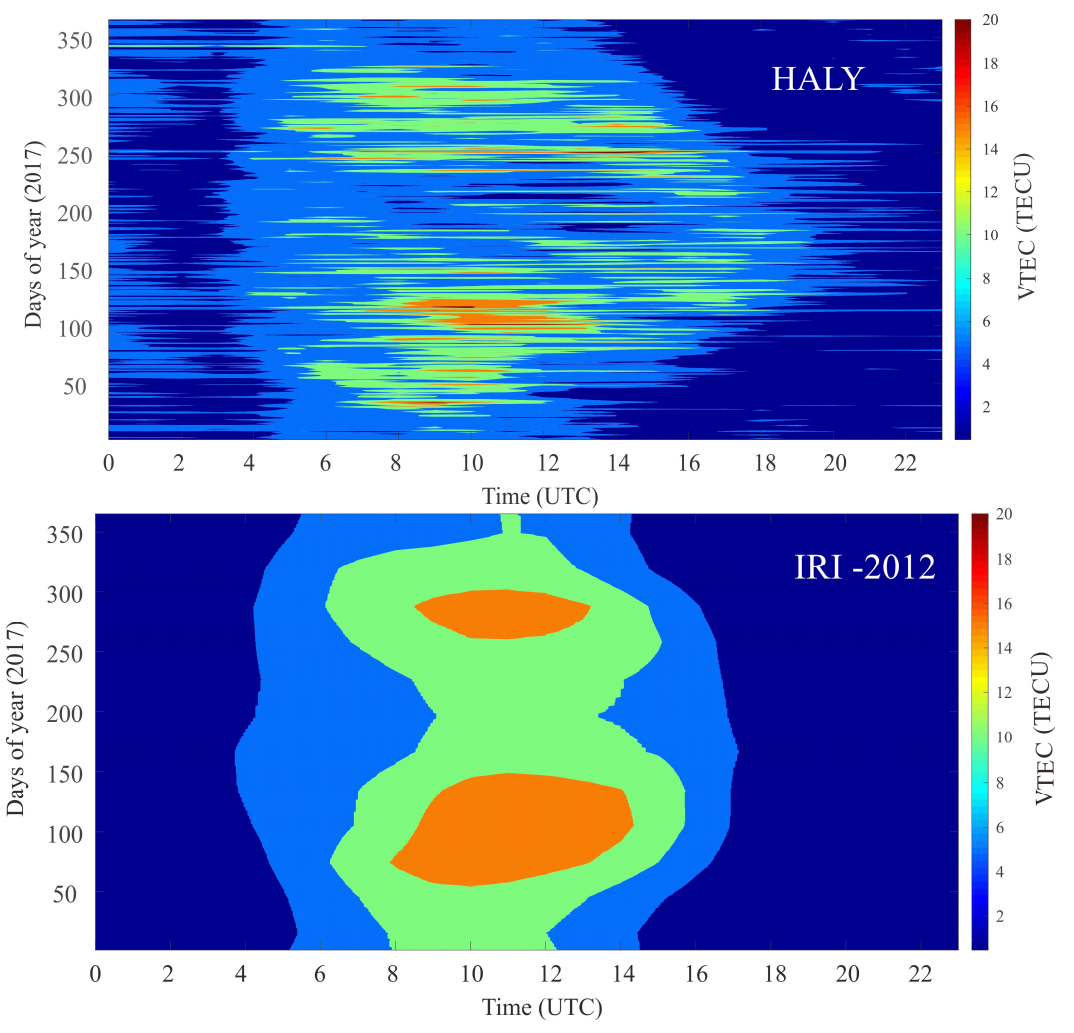




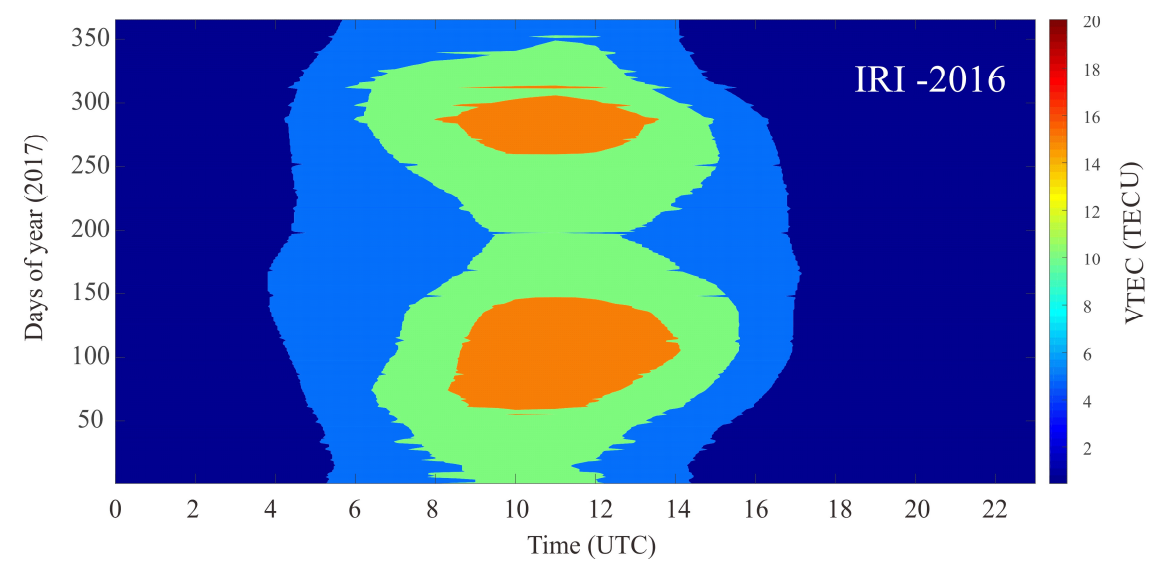

Figure 2. (a, b \& c), Diurnal VTEC Variation at HALY GPS site over Al-Jouf Saudi Arabia.

\subsection{Monthly VTEC variation}

Monthly average VTEC variation at the GPS site HALY and their corresponding IRI-2012 and IRI-2016 plots, from March 2016 to February 2018, have been shown in Fig. 3a, 3b \& 3c. It may be observed that VTEC variation was the highest (about 22 TECU) during March 2016 to May 2016 in plots indicating high solar activity time. It started to decrease slowly and become the lowest (about 5 TECU) during November 2016 to January 2017. Although the IRI models do not show significant decrement, they decreased in the same pattern as observed GPS-VTEC. Again, in March 2017, the VTEC became high (about 12 TECU) but not as much as in March 2016, indicating the solar activity period. The years of 2010-2018 over South Korea were of low and high solar activity, as discussed by Ansari et al. [34]. The period from July 2017 to September 2017 showed low VTEC values (about 5 TECU), and after that it started to increase again during November 2017. The VTEC value has been noticed to be low during January 2018 to February 2018, again reaching about 5 TECU. The corresponding IRI plots showed almost the same pattern, but they showed higher values than the GPS ones. Overestimation by IRI models, as compared to GPS data, has been reported by many studies [35-38].

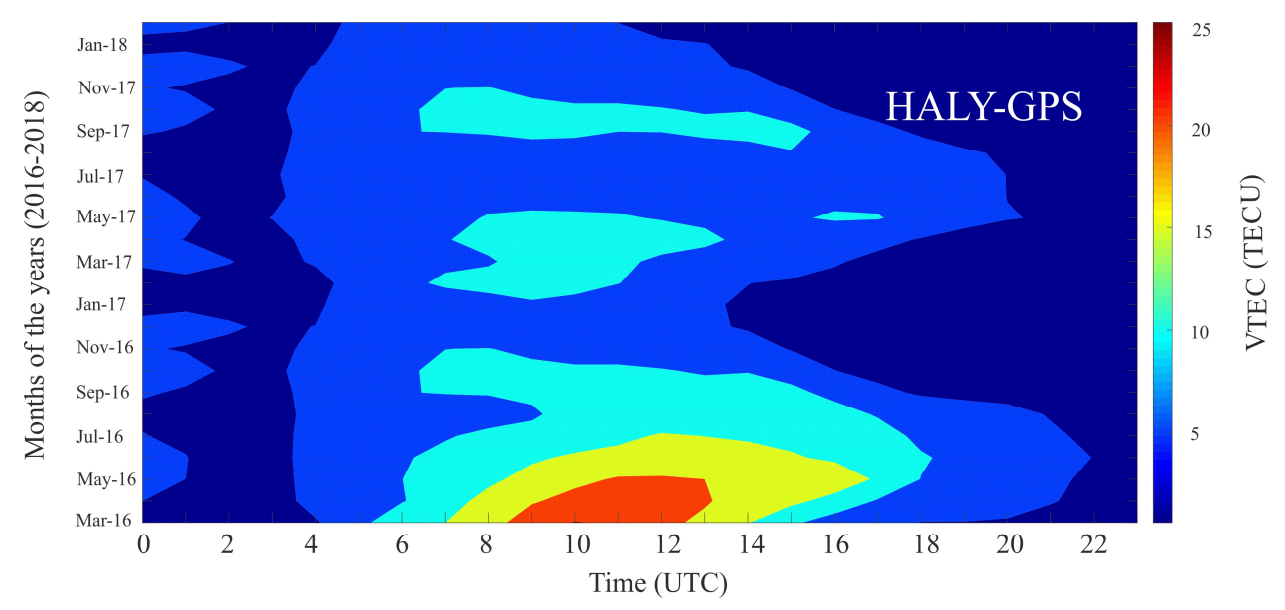



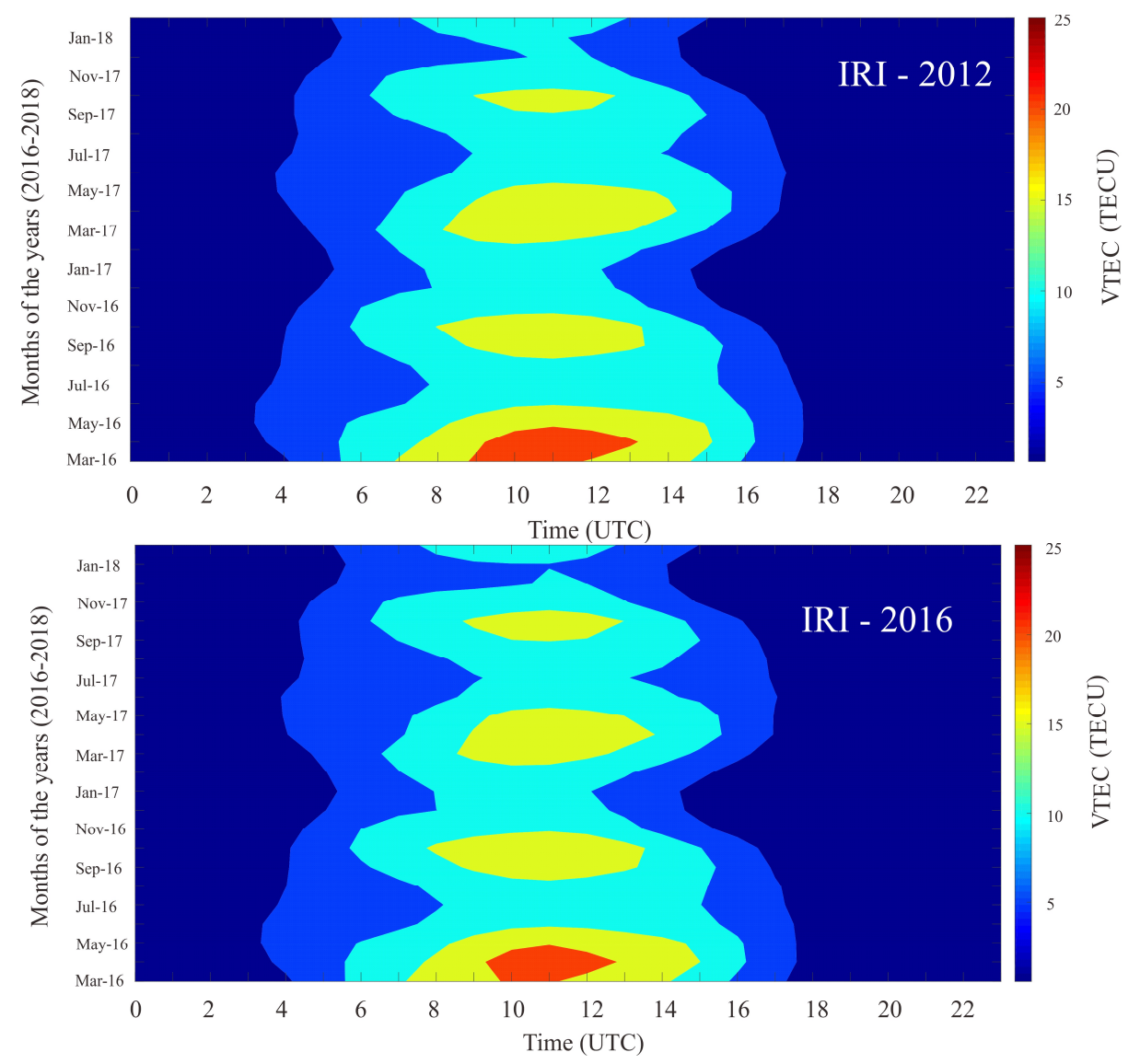

Figure 3. $(a, b$ \& c), Monthly VTEC Variation at HALY GPS site over Al-Jouf Saudi Arabia.

Monthly percentage deviation between GPS-VTEC verses IRI models was calculated by using equation (2) and plotted in Figs. $4 \mathrm{a} \& 4 \mathrm{~b}$. Positive percentage deviation means the GPS VTEC are overestimated, and vice versa. It is clear from the figures that the GPS VTEC values were overestimated during the late night (18:00 UT-24.00 UT) and morning period (00:00 UT-03:00 UT), by up to $50 \%$. This estimation started to decrease and became 0 during the period 03:00 UT to 05:00 UT at the start of the day and 16:00 UT-17:00 UT at the end. The percentage deviation was negative between the hours of 06:00 UT to 16:00 UT and reached up to more than 100\%. In January 2018, the deviation suddenly became as high as $200 \%$ (negative), which was enormous. The relatively large deviation of VTEC corresponded to the storm effect, which prompted the penetration of electric field, followed by enhanced Fountain effects [29].

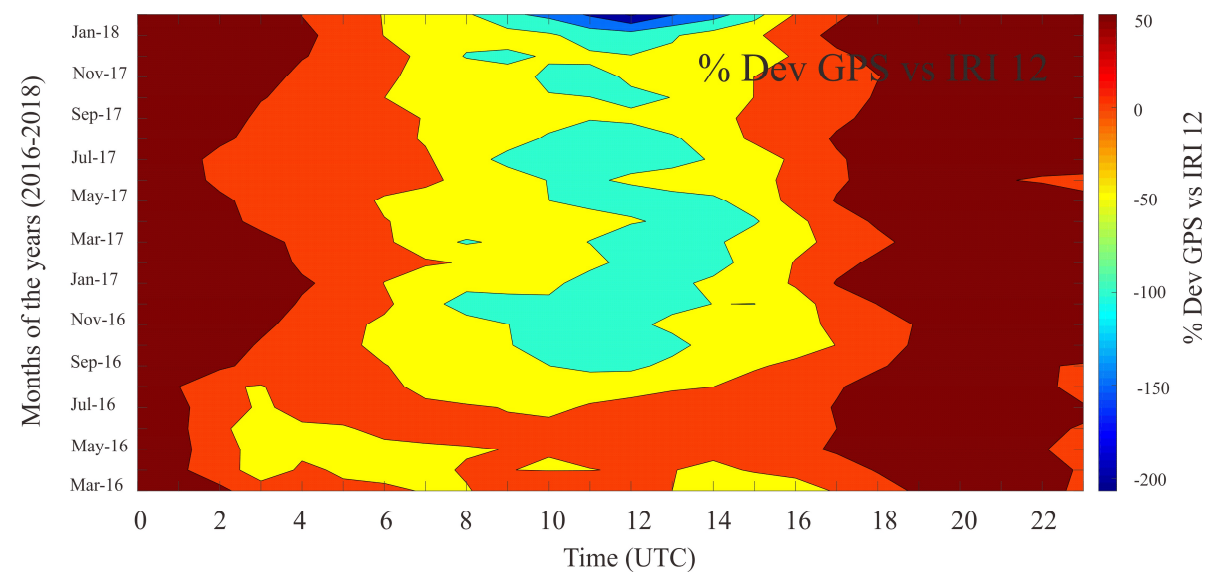




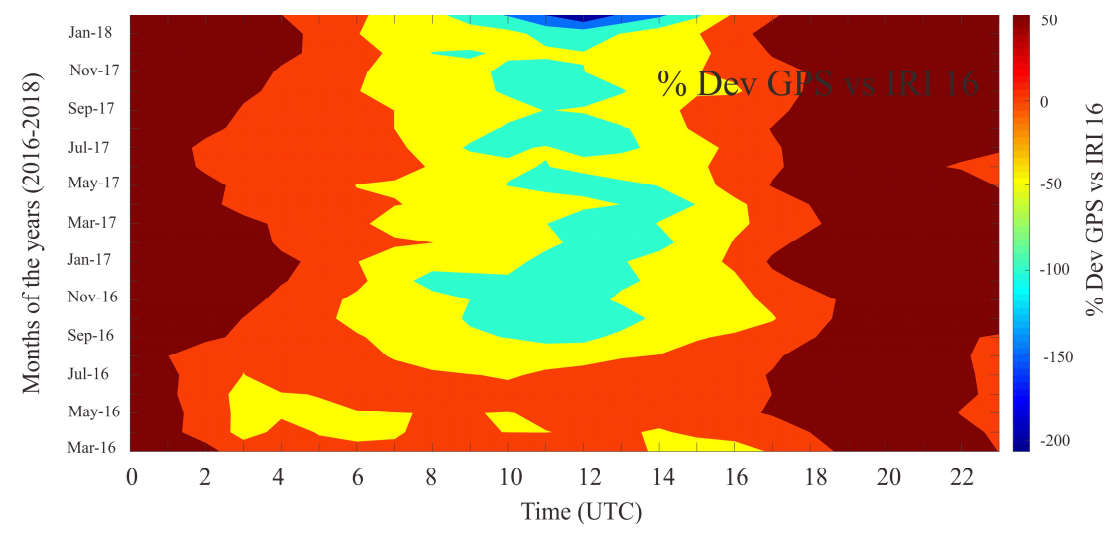

Figure 4. (a, \& b), Monthly VTEC deviation at HALY GPS site over Al-Jouf Saudi Arabia.

\subsection{Seasonal VTEC variation}

The incidence of seasons is due to the Earth rotation and its tilted axis by about 23.5 degrees toward, or away from the Sun through the annual orbit of Earth around the Sun. The seasonal average of VTEC values over the selected study period has been plotted in Fig .5. Clearly, the VTEC value started from 5 TECU and reached up to about 15 TECU during the March equinox during the daytime, while during the September equinox, the VTEC touched 11 TECU. Several studies across several regions have come up with similar findings, i.e., higher VTEC values during the March equinox as compared to the September equinox [34,39]. Within the solstice seasons, the June solstice showed the highest TEC values (about 13 TECU) while the December solstice reached up to only 9 TECU. The June solstice is greater which means disappearance of winter anomalies which has been discussed in many studies [38, 40]

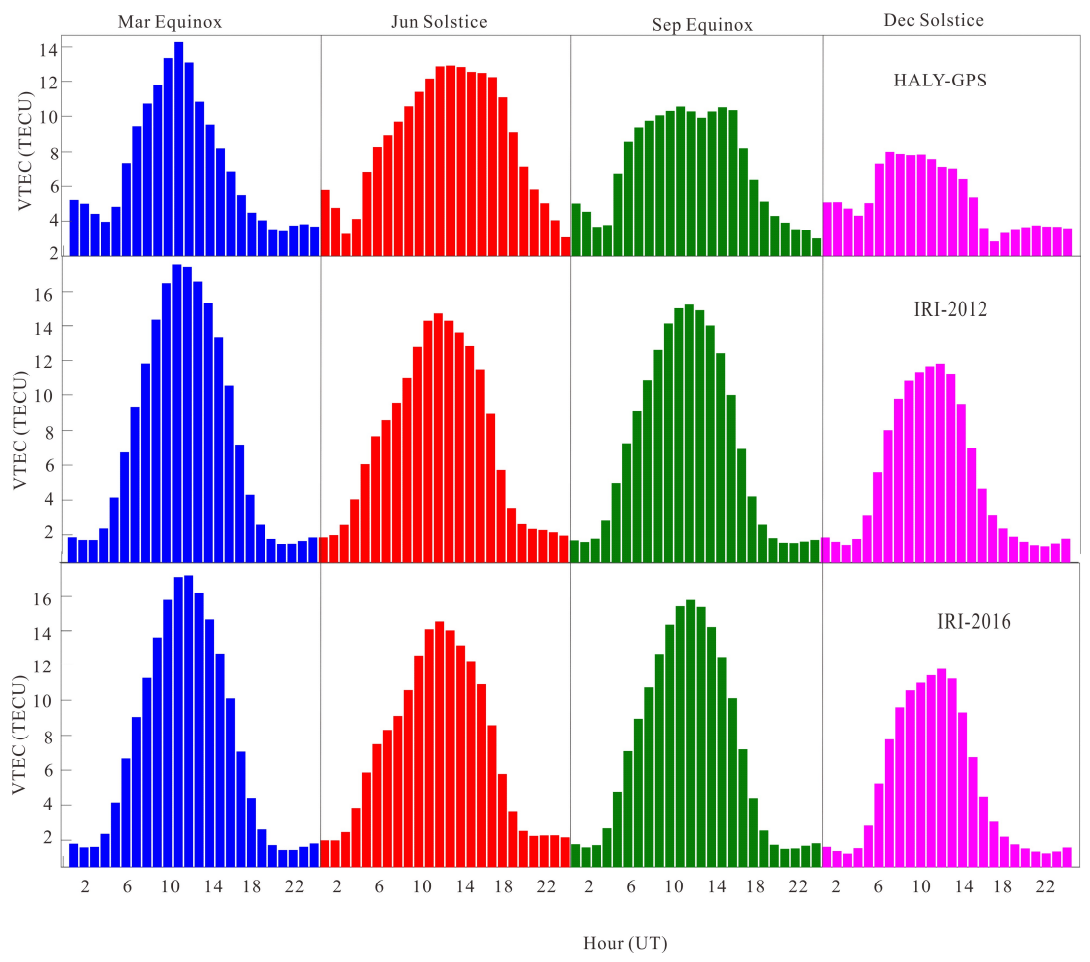

Figure 5. Seasonal VTEC Variation at HALY GPS site over Al-Jouf Saudi Arabia

We estimated Root Mean Square Error (RMSE) between the seasonal observed values and values obtained from the IRI models by using Eq. (3). Such separate differences have worked as estimated 
and residuals the prediction errors. RMSE helped to collect the magnitudes of the errors in predictions and is a good portion of accuracy. The seasonal variations of RMSE values of IRI-2012 and IRI-2016 models to measure GPS-TEC is shown in Table 1. It is clear from the table that the IRI 2012 model showed the lowest value (2.7437) during the September Equinox while IRI-2016 had highest RMSE magnitudes (3.0166) during the December Solstice. This could be due to the more disturbed GPS observed data at this time. At some season, the RMSE values are better in IRI 2012 and some of them it is better from 2016. Clearly, such variations indicate that even the most updated IRI 2016 model could not arrive at the most perfect estimations and more research is required to improve the same.

Table 1. Seasonal RMSE at HALY GPS site over Al-Jouf Saudi Arabia.

\begin{tabular}{ccccc}
\hline IRI Models & Mar Equinox & Jun Solstice & Sep Equinox & Dec Solstice \\
\hline IRI 2012 & 2.8214 & 3.1519 & 2.7437 & 2.8811 \\
\hline IRI 2016 & 2.8660 & 2.9359 & 2.7673 & 3.0166 \\
\hline
\end{tabular}

\section{Conclusion:}

The current study investigates the ionospheric variations from April 2016 to February 2018 (almost 22 months) over a GPS site HALY, Al-Jouf, Saudi Arabia. Observed results were further analyzed and validated using the outputs from existing IRI global models. The summary and conclusion of the results are as follows:

- Diurnal ionospheric variation shows that the VTEC varied from around 1 TECU and went as high as 20 TECU. At the commencement of the day, i.e., 0.00 UT, the VTEC variation remained low till $4.00 \mathrm{UT}$, consistently showing the same pattern throughout the year. It may be noticed that the VTEC was rather high between the periods 7.00 UT to 13.00 UT. The VTEC value touched around 12 TECU on the $50^{\text {th }}$ day of the year and sometime around 18 TECU between the $100-150^{\text {th }}$ days.

- Monthly average VTEC variation was the highest (about 22 TECU) during March 2016 to May 2016 in plots indicating high solar activity time. It started to decrease slowly and become lowest (about 5 TECU) during November 2016 to January 2017. Again, in March 2017 the VTEC become high (about 12 TECU) but not as compare to March 2016 indicate the solar activity period.

- The seasonal average VTEC started from 5 TECU and reached up to about 15 TECU during the March equinox in the daytime, while during the September equinox, the VTEC was about 11 TECU. Within the solstice seasons, the June solstice showed the highest TEC values of about 13 TECU while during the December solstice, this value reached up to only 9 TECU.

- Monthly percentage deviation between GPS-VTEC versus IRI models were overestimated by up to $50 \%$ during the late hours of the night (18:00 UT-24.00 UT) and morning time (00:00 UT-03:00 UT). The percentage deviation was negative between the hours 06:00 UT to 16:00 UT and reached up to more than $100 \%$. The deviation suddenly became as enormous as $200 \%$ negative, which corresponded to the storm effect.

- The IRI 2012 model showed lowest RMSE value (2.7437) during the September Equinox while IRI-2016 has highest RMSE magnitudes (3.0166). For some seasons, the RMSE values were found to be more accurately estimated by IRI 2012 while on other occasions, IRI 2016 fared better.

Acknowledgments: This work was financially supported by the Deanship of Scientific Research (DSR), Majmaah University, Majmaah -11952, Saudi Arabia, under Project No. 1439/52.

\section{References}

\section{References}

1. Bevis M, Businger S, Chiswell S, Herring T A, Anthes R A, Rocken C, \& Ware R H (1994). GPS meteorology: Mapping zenith wet delays onto precipitable water. Journal of applied meteorology, 33(3), 379-386. 
2. Bevis M, Businger S, Herring T A, Rocken C, Anthes R A, \& Ware R H (1992). GPS meteorology: Remote sensing of atmospheric water vapor using the Global Positioning System. Journal of Geophysical Research: Atmospheres, 97(D14), 15787-15801.

3. Koulali A, Ouazar D, Bock O, \& Fadil A. (2012). Study of seasonal-scale atmospheric water cycle with ground-based GPS receivers, radiosondes and NWP models over Morocco. Atmospheric research, 104, $273-$ 291.

4. Rohm W, Yuan Y, Biadeglgne B, Zhang K, \& Le Marshall J. (2014). Ground-based GNSS ZTD/IWV estimation system for numerical weather prediction in challenging weather conditions. Atmospheric Research, 138, 414-426.

5. Ansari K, Althuwaynee O F, \& Corumluoglu O (2016). Monitoring and prediction of precipitable water vapor using GPS data in Turkey. Journal of applied geodesy, 10(4), 233-245. ;https://doi: 10.1515/jag-2016-0037

6. Ansari K, Corumluoglu O, Panda S K, \& Verma P (2018). Spatiotemporal variability of water vapor over Turkey from GNSS observations during 2009-2017 and predictability of ERA-Interim and ARMA model. The Journal of Global Positioning Systems, 16(1), 8. https://doi.org/10.1186/s41445-018-0017-4

7. Solheim F S, Vivekanandan J, Ware R H, \& Rocken C. (1999). Propagation delays induced in GPS signals by dry air, water vapor, hydrometeors, and other particulates. Journal of Geophysical Research: Atmospheres, 104(D8), 9663-9670.

8. Brenot H, Ducrocq V, Walpersdorf A, Champollion C, \& Caumont O. (2006). GPS zenith delay sensitivity evaluated from high-resolution numerical weather prediction simulations of the 8-9 September 2002 flash flood over southeastern France. Journal of Geophysical Research: Atmospheres, 111(D15). http://dx.doi.org/10.1029/2004JD005726

9. Champollion C, Masson F, Van Baelen J, Walpersdorf A, Chéry J, \& Doerflinger E (2004). GPS monitoring of the tropospheric water vapor distribution and variation during the 9 September 2002 torrential precipitation episode in the Cévennes (southern France). Journal of Geophysical Research: Atmospheres, 109(D24).

10. Mukul M, Jade S, Ansari K, \& Matin A. (2014). Seismotectonic implications of strike-slip earthquakes in the Darjiling-Sikkim Himalaya. Current Science, 198-210.

11. Mukul M, Jade S, Ansari K, Matin A, \& Joshi V. (2018). Structural insights from geodetic Global Positioning System measurements in the Darjiling-Sikkim Himalaya. Journal of Structural Geology, 114, 346-356. https://doi.org/10.1016/j.jsg.2018.03.007

12. Ansari K (2018). Crustal deformation and strain analysis in Nepal from GPS time-series measurement and modeling by ARMA method. International Journal of Earth Sciences, 107(8), 2895-2905. https://doi.org/10.1007/s00531-018-1633-7

13. Ansari K, Corumluoglu O, \& Sharma S K (2017). Numerical simulation of crustal strain in Turkey from continuous GNSS measurements in the interval 2009-2017. Journal of Geodetic Science, 7(1), 113-129. https://doi.org/10.1515/jogs-2017-0013

14. Bilitza D, Altadill D, Truhlik V, Shubin V, Galkin I, Reinisch B, \& Huang X (2017). International Reference Ionosphere 2016: From ionospheric climate to real-time weather predictions. Space Weather, 15(2), 418-429.

15. Bilitza D, Altadill D, Zhang Y, Mertens C, Truhlik V, Richards P, ... \&Reinisch B. (2014). The International Reference Ionosphere 2012-a model of international collaboration. Journal of Space Weather and Space Climate, 4, A07. https://doi.org/10.1051/swsc/201400

16. Bilitza D, McKinnell L A, Reinisch B, \& Fuller-Rowell T. (2011). The international reference ionosphere today and in the future. Journal of Geodesy, 85(12), 909-920.

17. Kouris S S, Xenos T D, Polimeris K V \& Stergiou D. (2004). TEC and foF2 variations: preliminary results. Annals of Geophysics.

18. Lin, J.W., 2013. Ionospheric anomaly related to $M=6.6,26$ August 2012, Tobelo earthquake near Indonesia: two-dimensional principal component analysis. Acta Geodaetica et Geophysica, 48(3), pp.247-264.

19. Kamide, Y., Yasuhara, F., Akasofu, S.-I., 1974. On the cause of northward magnetic field along the negative $\mathrm{X}$ axis during magnetospheric substorms. Planet. Space Sci. 22, 1219-1229.

20. Karia S P, Patel N C, \& Pathak K N (2015). Comparison of GPS based TEC measurements with the IRI-2012 model for the period of low to moderate solar activity (2009-2012) at the crest of equatorial anomaly in Indian region. Advances in Space Research, 55(8), 1965-1975. 
21. Tariku Y A (2015). Patterns of GPS-TEC variation over low-latitude regions (African sector) during the deep solar minimum (2008 to 2009) and solar maximum (2012 to 2013) phases. Earth, Planets and Space, 67(1), 35. https://doi.org/10.1186/s40623-015-0206-2

22. Wichaipanich N, Hozumi K, Supnithi P, \&Tsugawa T (2017). A comparison of neural network-based predictions of foF2 with the IRI-2012 model at conjugate points in southeast asia. Advances in Space Research, 59(12), 2934-2950. https://doi.org/10.1016/j.asr.2017.03.023

23. Kumar S, Singh A K, \& Lee J (2014). Equatorial Ionospheric Anomaly (EIA) and comparison with IRI model during descending phase of solar activity (2005-2009). Advances in Space Research, 53(5), 724-733.

24. Alcay S, Oztan G, \& Selvi H Z (2017). Comparison of IRI_PLAS and IRI_2012 model predictions with GPSTEC measurements in different latitude regions. Annals of Geophysics, 60(5), 0549. https://doi.org/10.4401/ag-731120.

25. Paul, B., De, B.K. and Guha, A., 2018. Latitudinal variation of F-region ionospheric response during three strongest geomagnetic storms of 2015. Acta Geodaetica et Geophysica, 53(4), pp.579-606.

26. Şentürk, E. and Çepni, M.S., 2018. Ionospheric temporal variations over the region of Turkey: a study based on long-time TEC observations. Acta Geodaetica et Geophysica, 53(4), pp.623-637

27. Reddybattula K D, Panda S K, Ansari K, \& Peddi V S R (2019). Analysis of ionospheric TEC from GPS, GIM and global ionosphere models during moderate, strong, and extreme geomagnetic storms over Indian region. Acta Astronautica. https://doi.org/10.1016/j.actaastro.2019.05.042

28. Inyurt, S. and Sekertekin, A., 2019. Modeling and predicting seasonal ionospheric variations in Turkey using artificial neural network (ANN). Astrophysics and Space Science, 364(4), p.62.

29. Sharma S K, Ansari K, \& Panda S K (2018). Analysis of Ionospheric TEC Variation over Manama, Bahrain, and Comparison with IRI-2012 and IRI-2016 Models. Arabian Journal for Science and Engineering, 43(7), 38233830., https://doi.org/10.1007/s13369-018-3128-z

30. Seemala G K, \& Valladares C E (2011). Statistics of total electron content depletions observed over the South American continent for the year 2008. Radio Science, 46(5). https://doi.org/10.1029/2011RS004722

31. Akala, A.O., Somoye, E.O., Adewale, A.O., Ojutalayo, E.W., Karia, S.P., Idolor, R.O., Okoh, D. and Doherty, P.H., 2015. Comparison of GPS-TEC observations over Addis Ababa with IRI-2012 model predictions during 2010-2013. Advances in Space Research, 56(8), pp.1686-1698.

32. Chauhan V, \& Singh O P (2010). A morphological study of GPS-TEC data at Agra and their comparison with the IRI model. Advances in Space Research, 46(3), 280-290.

33. Razin, M.R.G. and Voosoghi, B., 2017. Regional ionosphere modeling using spherical cap harmonics and empirical orthogonal functions over Iran. Acta Geodaetica et Geophysica, 52(1), pp.19-33.

34. Ansari K, Park K D, \& Panda S K (2019). Empirical Orthogonal Function analysis and modeling of ionospheric TEC over South Korean region. Acta Astronautica, 161 (2019), 313-324, https://doi.org/10.1016/j.actaastro.2019.05.044

35. Abdu, M.A., Batista, I.S. and De Souza, J.R., 1996. An overview of IRI-observational data comparison in American (Brazilian) sector low latitude ionosphere. Advances in Space Research, 18(6), pp.13-22.

36. Ansari K, \& Park K. D. (2018). Multi constellation GNSS precise point positioning and prediction of propagation errors using singular spectrum analysis. Astrophysics and Space Science, 363(12), 258. https://doi.org/10.1007/s10509-018-3479-7

37. Bhuyan P K, \& Borah R R (2007). TEC derived from GPS network in India and comparison with the IRI. Advances in Space Research, 39(5), 830-840.

38. Kumar S, Patel K, \& Singh A K (2016). TEC variation over an equatorial and anomaly crest region in India during 2012 and 2013. GPS solutions, 20(4), 617-626. doi:10.1007/s10291-015-0470-4

39. Sharma S K (2019). Ionospheric TEC variation over Manama, Bahrain and comparison with NeQuick-2 model. Astrophysics and Space Science, 364(1), 16. https://doi.org/10.1007/s10509-019-3503-6

40. Bagiya M S, Joshi, H P, Iyer K N, Aggarwal M, Ravindran S, \& PathanB. M. (2009, March). TEC variations during low solar activity period (2005-2007) near the equatorial ionospheric anomaly crest region in India. In Annales Geophysicae (Vol. 27, No. 3, pp. 1047-1057). Copernicus GmbH. http://www.anngeophys.net/27/1047/2009 